\title{
A noninvasive tonometer in the measurement of the effects of pindolol and timolol on intraocular pressure in normal subjects
}

\author{
S. ROWLEY, J. E. STAUnton, A. TOSCH, J. H. STEWART-JONES, \\ D. F. EDGAR, AND P. TURNER \\ From the Department of Optometry and Visual Science, City University, \\ and the Department of Clinical Pharmacology, St Bartholomew's Hospital, London EC1A 7BE
}

SUMmARY A noncontact tonometer was used to demonstrate in normal human volunteers the ocular hypotensive effects of single instillations of pindolol $(1 \%)$ and timolol $(0.25$ and $0.5 \%)$ eye drops. Falls in intraocular pressure were significantly correlated with resting intraocular pressure. Evidence of systemic cardiovascular effects was seen in reductions in resting heart rate.

The measurement of changes in intraocular pressure is important in the screening of drugs that may reduce pressure and so be of therapeutic value in the treatment of glaucoma, and of drugs that possess atropine-like effects and so have the potential to raise intraocular pressure and precipitate glaucoma in patients at risk. Although changes in intraocular pressure may be measured by a contact tonometer, this requires the production of local corneal anaesthesia before its application and has been criticised as possibly leading to changes in corneal permeability to other drugs. A noncontact tonometer has been described ${ }^{1}$ which depends on the dispersion following reflection of a collimated beam of light directed at the cornea when the corneal surface is flattened by a pulsed column of compressed air. Preliminary studies suggested that this method was sensitive enough to demonstrate an ocular hypotensive action of beta adrenoceptor antagonist atenolol in normal volunteers. ${ }^{2}$ This paper describes further studies designed to confirm the validity of this method and its acceptibility to normal subjects.

\section{Materials and methods}

The subjects were healthy young volunteers of both sexes aged 18-40 years, without evidence of ophthalmic abnormalities, and with no history of bronchial asthma. Each subject was screened in preliminary

Correspondence to Professor P. Turner, Department of Clinical Pharmacology, St Bartholomew's Hospital Medical College, London EC1A 7BE. tests so that those in whom 5 consecutive measurements showed a difference of more than $3 \mathrm{mmHg}$ were excluded. Measurements in 62 of 94 eyes showed a variation of $3 \mathrm{mmHg}$ or less, and these were considered suitable for the definitive studies. All preparations were administered by a third party to ensure double-blindedness on the part of subject and investigator, and were instilled into the left eye. Intraocular pressure ${ }^{13}$ and radial pulse rate over 1 minute after 5 minutes at rest (sitting) were measured before and at 30,60 , and 90 minutes after drug instillation. Three recordings of intraocular pressure in each eye were taken on each occasion and the means recorded.

Two studies were carried out, the first comparing timolol 0.25 and $0.5 \%$ with normal saline, and the second pindolol $1 \%$, timolol $0.25 \%$, and normal saline. In each study 12 subjects were studied, no subjects taking part in more than 1 study. They attended on 3 occasions at least 1 week apart for instillation of 1 drop into the conjunctival sac (a) timolol $0.25 \%, 0.5 \%$, or saline $0.9 \%$, or $(b)$ pindolol $1 \%$, timolol $0.25 \%$, or saline $0.9 \%$, given in a balanced design based on 4 Latin squares.

\section{Results}

TIMOLOL $0.25 \%$ VERSUS $0.5 \%$ VERSUS SALINE Changes in the intraocular pressure between the treated (left) eye and untreated (right) eye after instillation of drug or saline are shown in Fig. 1. There was a concentration-related fall in pressure 


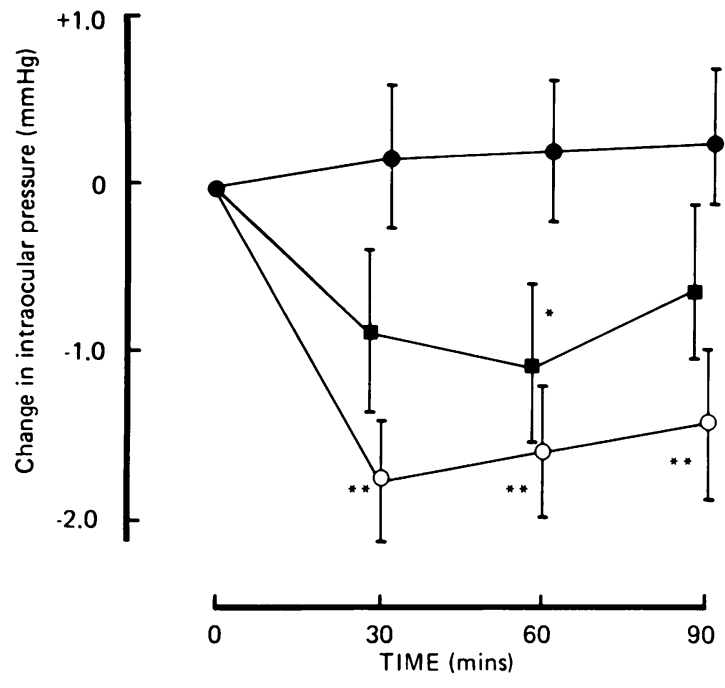

Fig. 1 Differences in mean $( \pm S E M)$ intraocular pressure $(\mathrm{mmHg})$ between the treated and untreated eyes before and at 30,60, and 90 minutes after instillation of saline $(\mathrm{O})$, timolol $0.25 \%(\mathrm{O})$, and timolol $0.5 \%(\mathrm{O})$. ${ }^{*} p<0.05,{ }^{* *} p<0.02$ when compared with saline. after timolol administration, $0.5 \%$ producing significant changes at 30,60 , and 90 minutes $(\mathrm{p}<0.02)$ and $0.25 \%$ at 60 minutes $(\mathrm{p}<0.05)$ when compared with saline, which produced no significant change. The changes produced by both concentrations in all subjects showed a significant correlation between fall in pressure and resting intraocular pressure $(r=0.70, p<0 \cdot 01)$. No significant changes were found in pulse rate after either drug concentration when compared with saline.

PINDOLOL $1 \%$ VERSUS TIMOLOL $0.25 \%$ VERSUS SALINE

Both active treatments produced a similar fall in intraocular pressure (Fig. 2), the reduction being significant at 60 minutes $(\mathrm{p}<0.02$ for pindolol, $\mathrm{p}<0.05$ for timolol). There was no significant difference between the 2 active treatments. Saline produced no significant change. The falls in pressure produced by both drugs showed a significant correlation with resting pressure $(r=0.87, p<0.01)$. Timolol produced a small but significant fall in pulse rate at 60 minutes when compared with saline (mean fall $=3.9$ beats $/$ min, SE $1.73, \mathrm{p}<0.05$ ), but

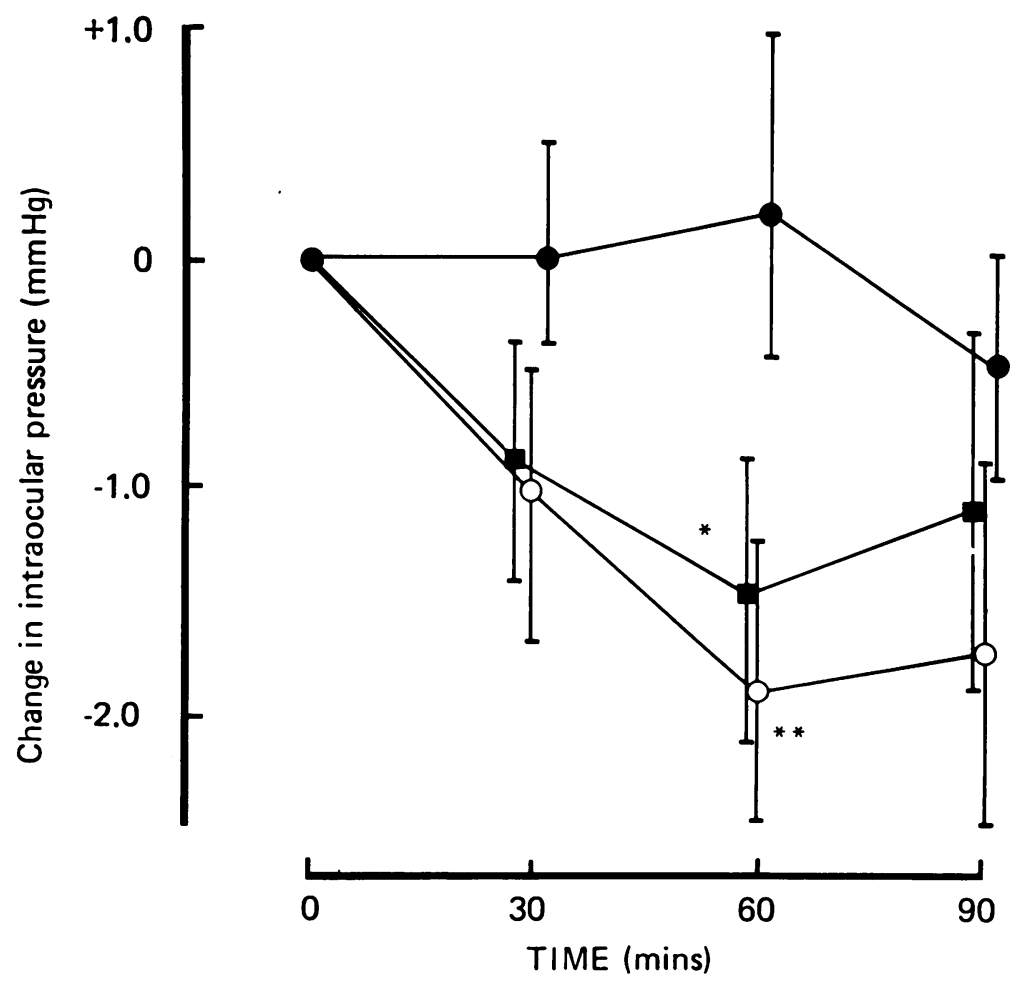

Fig. 2 Differences in mean ( $\pm S E M)$ intraocular pressure $(\mathrm{mmHg})$ between the treated and untreated eyes before and at 30, 60 , and 90 minutes after instillation of saline $(\mathbf{O})$, timolol $0.25 \%(\square)$, and pindolol $1 \%(\mathrm{O}) .{ }^{*} p<0.05$, ${ }^{* *} p<0.02$ when compared with saline. 
similar mean changes produced by pindolol were not statistically significant.

\section{Discussion}

These results confirm the ability of the noncontact tonometer used to distinguish the ocular hypotensive effects of active from inactive treatments in normal subjects under double-blind conditions, and to establish concentration-response relationships. Subjects were chosen in whom preliminary testing had shown a consistency of readings of intraocular pressure, those with variations of more than $3 \mathrm{mmHg}$ over 5 consecutive measurements being excluded. More than $60 \%$ of the eyes tested showed a variation of $3 \mathrm{mmHg}$ or less and were considered acceptable for the studies. This may have improved the sensitivity of the method in our hands but must be tested in further controlled studies.

A further validation of the method is seen in the significant positive correlation found between the resting intraocular pressure and the fall produced by both beta-blocking drugs, subjects with the highest resting pressures having the greatest falls in pressure.

The systemic effects of beta-blocking drugs administered by local ocular instillation were confirmed by the significant fall in pulse rate produced in timolol in one study. Similar cardiovascular effects have been found after local instillation of pindolol. ${ }^{4}$

The similarity of the ocular hypotensive effects of timolol $0.25 \%$ and pindolol $1 \%$ found in this study confirms the results of a preliminary study in 8 subjects, ${ }^{5}$ and it suggests that timolol is a more potent ocular hypotensive agent than pindolol. However relative potencies cannot be established on the basis of studies with single concentrations alone, and further studies with other concentrations of pindolol are planned. Pindolol differs from timolol in having marked partial agonist activity, and it is possible that this may influence its action, although until the mechanism of its ocular hypotensive effects are established this must remain uncertain.

We thank Merck Sharpe and Dohme Ltd and Sandoz Products Ltd for supplying timolol and pindolol, and Miss S. Tree of the Pharmacy Department, St Bartholomew's Hospital, for assistance with preparing the pindolol ophthalmic solution.

\section{References}

1 Grolman B. A new tonometer system. Am J Optom Physiol Opt 1972; 49: 646-50.

2 Hill SEW, Lewis K, Stewart-Jones JH, Wadsworth J, Turner P. Effect of local atenolol on intraocular pressure in normal subjects using a non-invasive method. Pharmatherapeutica 1979 ; 2 : 136-9.

3 Myers KJ. Repeatability of IOP measurement with the non-contact tonometer. Am J Optom Physiol Opt 1974; 51: $39-48$.

4 Smith SE, Smith SA, Reynolds F, Whitmarsh K. Ocular and cardiovascular effects of local and systemic pindolol. Br J Ophthalmol 1979; 63: 63-6.

5 Rowley SN. Comparison of the effects of beta adrenergic blockade with timolol or pindolol on pupil size, accommodation and intraocular pressure. B.Sc. project. London: City University, 1979. 